\title{
Research on the Packaging and Illustration Design Development Trend from the Psychology and Aesthetics Perspectives
}

\author{
Yixin $\mathrm{Wu}^{1}$ \\ ${ }^{1}$ Nanchang media, Career Academy, Jiangxi, \\ Jiangxi Province 330224 China
}

\begin{abstract}
In this paper, we conduct research on the packaging and illustration design development trend from the psychology and aesthetics perspective. Commercial illustration in packaging design which can provide extremely diversified forms of style, to convey the brand's core idea, brand or product difference, and brand personality. Application of illustration in packaging design should use human language, which would make the commodity characteristics. Our methodology combines the principles of psychology and aesthetics to optimize the traditional approaches which will not only enhance the design pattern of the current model and help make innovative products.
\end{abstract}

Keywords: Packaging and Illustration Design; Psychology and Aesthetics; Literature Review.

\section{Introduction}

In the field of modern design, commercial illustration is the most can reflect times graphic language. It stood in expressing the forefront of the times, beyond the language and the theme, reflects the generalization of visual communication, is beyond the design of the popular and superficial, in the design reflect spirit of The Times and resonates with consumers, aftertaste making a person is. Commercial illustration in packaging design which can provide extremely diversified forms of style, to convey the brand's core idea, brand or product difference, and brand personality. Illustration from the perspective of the development of history, this kind of design at first is in the service of the spread of religion, with the development of printing technology, illustrations attached to books, magazines, newspapers and other printed matter and get great performance space which will become one of the main elements of visual art print media. Illustrations, early also known as illustrations, usually pointed out that book now which has been added into words [1]. Later with the development of the society, the application of illustration in today's commercial activity has been further expanded, which appear in the magazines, clothing, film and television, music, advertising, packaging and other media, it involves content continues to increase, and gradually formed its own unique visual language and the technique of expression, gradually beyond its itself as a foil words role position, develop into visual art has stronger practicability. Illustrations on the packaging and the prototype of the in China can be traced back to the northern song dynasty in the shop wrapping paper on the small white rabbit pattern, or even earlier period the relics unearthed painted pottery basin on the face of the fish.

In modern times, with photography, due to the needs of the business, has left many packaging illustration content by is famous for its vivid and realistic pictures [2]. With the advent of new technologies, new illustration creation materials and tools, especially the use of computer technology and digital technology, let packaging once-sleepy illustrations in life again. Application of digital technology of digital illustration of the influence of packaging design is very profound. Reproduce the form of goods for the real, vivid commercial 
photography has become a very good choice; On the performance of commodity quality, in order to highlight its distinctive quality and connotation, take illustrations have focused on performance is a more effective approach. To performance, the theme of the illustrations used the technique more diverse and point of view which let the ideas and thinking much of play space and show stage. The juice drinks on the market today, for example, is targeted at young consumers, thus it can be use the technique of concise realism to depict its delicious and nutritious ingredients, with the aid of lively and tonal foil can cause loss of appetite [3].

Application of illustration in packaging design should use human language, which would make the commodity characteristics, core value perfectly, prompt consumers and commodities was quickly close the distance, improve consumer identity of goods, finally achieve the purpose of expanding sales. Human language used in the design of commodity packaging illustration is a newborn thing, in such aspects as design, use and there are many aspects worthy of our thinking and exploration. Should be according to the actual commodity packaging design work, spread to the discussion of the application and function of commodity packaging illustration, correct understanding the value of human language, in the design of commodity packaging illustration for using the population sex, nationality, individualized humanization language design of commodity packaging illustration, make packaging illustration design more humane language and make it more beneficial to promote the commodity for consumer recognition and expand the products in the market share and expand sales.
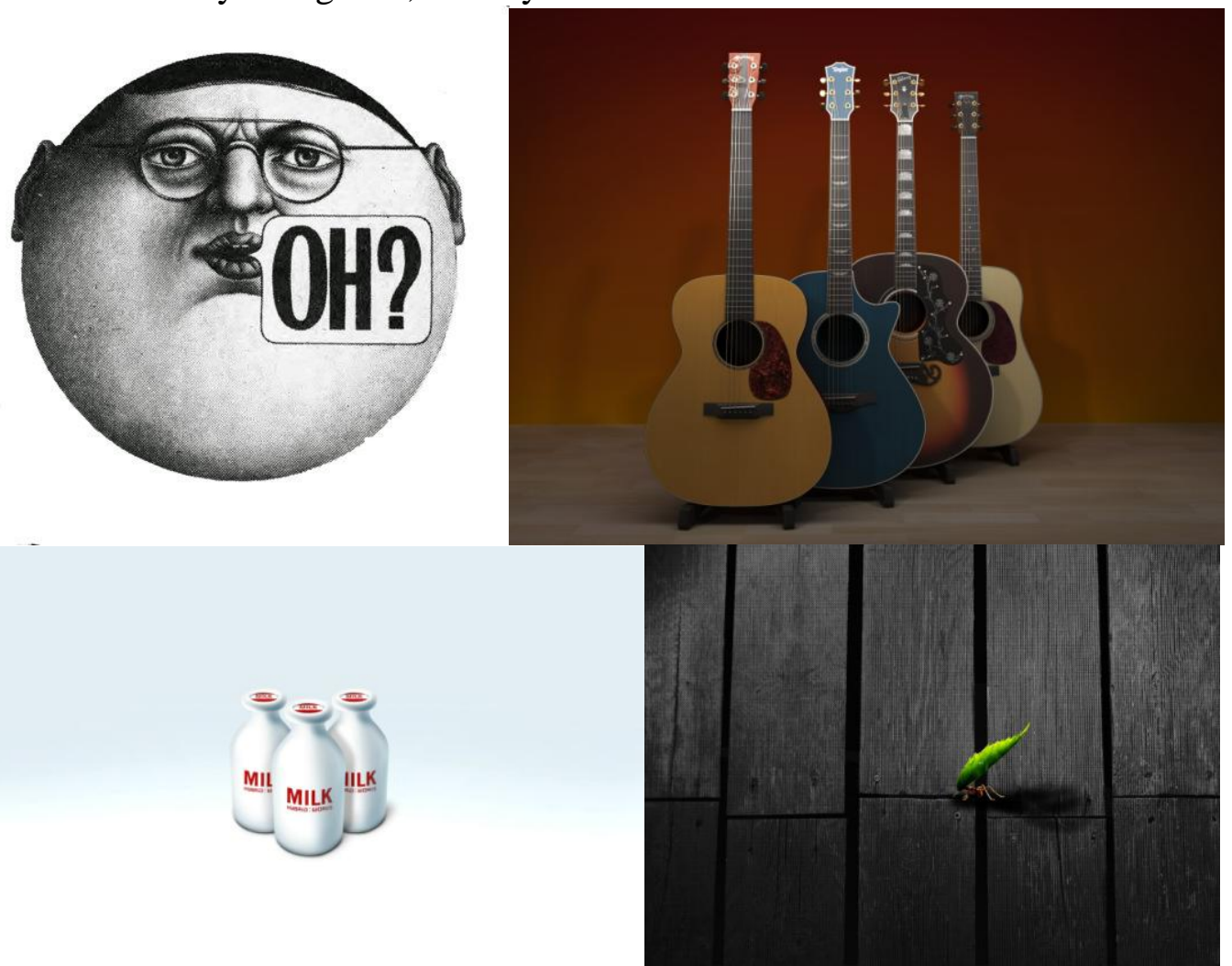

Figure 1. The Sample of Packaging and Illustration Design

In this paper, we conduct research on the packaging and illustration design development trend from the psychology and aesthetics perspective. In the process of the design of the packaged goods, on how to better conform to the national and regional characteristic of 
commodity is one of the important factors can cause consumer identity and resonance, packaging illustration of this aspect of human performance has its own way. The adornment style of illustration has a long history, has the national characteristics of different nationalities and other decorative decoration pattern, auspicious patterns, as well as folk paper-cutting style. Adornment style of all ethnic groups of different characteristics will reflect each nation strong national culture. In the following sections, we will discuss in detail.

\section{The Proposed Approach and Perspective}

Principles of Packaging and Illustration Design. People in daily life is to be exposed to a lot of product packaging and sales in an open environment, the lack of visual communication of product packaging and it is difficult to attract the attention of consumers in many related similar products. At the same time, the packing is also a corporate brand, market share, one of the important means of survival and development. Brand is the commodity of the perfect fusion of material function and culture symbol, consumers to buy is not only material goods, also is a kind of cultural spirit, the purchase and the material function of product packaging design in addition to performance and quality, also embodied the spirit of the enterprise and culture grade of the product. In the modern packaging design, designers use illustrations intuitive graphical language to the interpretation of enterprise culture idea, show the unique temperament and brand personality. On the premise of grasp the market demand change, use of illustrations guide consumers from the sensors and actuators, aesthetic, cultural and spiritual products experience of non-material function, make the consumer psychology and the spirit of the products, cultural functions organically unification, the fun of creating experience for consumers, to establish a long-term contact consumers and businesses and products. Illustration in packaging design is an indispensable important component, it can product content accurately and vividly reflect the basic information to consumers. Good illustration image can attract attention quickly, leave deep impression and win consumer goods to its favor.

Illustration with a strong flavor of commercial and practical is often not as a separate drawing performance. Compared with the realistic strong photography, commercial illustration has the advantage of flexibility, it make people in paintings to feel give full play to the imagination, adds consumer interest in the product, rich variety of products for consumers in the visual image can deepen understanding and memory, also can bring consumers a strong identity, increase the affinity of products. And from the creation and operation of commercial illustration whole process point of view, for the enterprise or product drawing pictures, give up the ownership of works, the author reserves the right of authorship and receive relevant business practices at the same time, can be called a commercial illustrator. Commercial illustration to the spread of timeliness is relatively short compared to the other types of illustrations, when its service enterprise or product changes to replace, the work will be terminated propaganda spread lost its commercial value. But business illustrations with the packaging, advertising, film and television and other mass media dissemination, wide coverage, social interest is much higher than other kinds of the art of painting. As a result, commercial illustration in a short period of time a burst of light is can't be matched by other art paintings.

The Psychology and Aesthetics Perspectives. Illustration is a kind of visual art between design and photography. For performance object technique, technique and style is different and there are different classification compared with the realistic strong photography, illustration has the advantage of flexibility. The illustration form application form in the world of fashion could be separated into the following parts. (1) Fashion illustration today already is the art of micro, however we 
are still keen to draw inspiration from the past art and life. In the past we have always maintained a certain level of enthusiasm, probably because at that time the fashion is not like today so commercialized, has a unique character, placed the pursuit of good, is placed in the material relatively minor position, so they look so beautiful. (2) Artistic packaging illustration have involuntarily creative effect, conform to the point of view of psychology about all the people are eager to get rid of the bondage, has a good impression on the goods, is eternal and will never forget, to need, naturally want to buy this enterprise of the goods; Even you don't need the goods in terms of practical, also want to buy this goods, mainly in order to satisfy his own aesthetic need. (3) Illustration tools began to diversification and the realization of the illustration is no longer a single. At that time, social studies, a decorative design in this rapid development laid a solid foundation for illustration. Hence, illustration is no longer just as subservient to the product, but as an independent ideographic image, mounted the stage of art and design. (4) Fashion illustration of history with the birth of the world history of fashion shoots and common development in the early 16th century, has been published publications began to reflect different parts of the fashion illustration of cultural change.

The application of digital technology the influence of commercial digital illustration in packaging design is very profound with more free creation mode and implementation tools to change the general packing of the plane decoration design ideas and the way of thinking. A new design style and graphic language. Make the traditional packaging art aesthetic and visual experience has changed. Such as digital technology characteristics of the pixel image and mosaic graphics, deliberately applied to the packaging design by designer. At the same time along with the wide application of commercial illustration in packaging, packaging connotation has been extended. A good packaging illustration design guidance is of vital importance to consumer, striking illustration image can make consumer's attention is drawn in a relatively short time to live to consumers leave deep impression. It is a very broad, the packaging products cover all aspects of people's life and packaging is to make the product to market an important part. Holds read the nature of the contents are wrapped, the important thing is make sure the accuracy of the information, can be packing the contents of the general performance characteristics, source of raw materials, etc. It with words, colors and logos and other visual elements relate to each other which are mutually constituted the packing image of the whole business information to communicate to the consumer products. Packaging illustration can be cultivated in the consumer of the product, increase the emotional connection between enterprises and consumers, make the consumption object produces more buying needs and reach the consumer awareness.

The Development Trend and Prospect. Any of an artist to create works with our own nation, grew up thinking and folk characteristic and how many are affected, and the shadow of the nation and region. Thus, in the process of the design of the packing goods, for how to better conform to the national and regional characteristic of commodity is one of the important factors can cause consumer identity and resonance, packaging illustration of this aspect of human performance has its own way. The adornment style of illustration has a long history, has the national characteristics of different nationalities and other decorative decoration pattern, auspicious patterns, as well as folk paper-cutting style. It is big red bottom and more reflect a very strong Chinese flavor. Plus watercolor painting or local opera characters of Chinese traditional decoration with lace, deeply marked by the Chinese local brand. Illustration of multilateral fusion determines the contact more and more closely with other art forms, in the rapidly changing global market, as a direct impact on people's life and behavior of art "illustration art and clothing design", should 
be continually find combining site and collide each other of the two, with clothes of artistic language to interpret, the promotion of illustration, with illustrations of art clothing deconstruction behavior, innovation, in the face of contemporary art style diversification trend, China's garment industry should increase the design innovation, technology innovation, technology innovation, marketing innovation. Combining the independent innovation and industry innovation, to promote the popular clothing, achieve business value. In today's information age, along with the change of the pace of life and the development of information visualization, design is the application of digital technology to infiltrate every corner of our life. Digital visual graphics is accompanied by computing tent after the birth of technology and digital technology, the emergence of a new form of visual graphics.

\section{Conclusion}

In this paper, we conduct research on the packaging and illustration design development trend from the psychology and aesthetics perspective. In the style of variability is one of the remarkable features of digital business illustrations. It can draw lessons from illustration style and the spirit connotation is more artistic charm. It is necessary to study the application of laws and practices. In order to better penetrate the packaging art, so as to promote the commodity sales and service. To more profoundly reveal the nature of the goods, we can use many masters of painting style and excellent traditional culture resources, combined with their own design, with the performance of the different techniques to create more practical value of packaging products. Our proposed methodology deals with the mentioned drawbacks well which will be meaningful and necessary.

\section{References}

[1] Chen F. Existing Problems and Development Trend in Modern Art Packaging Design[J]. Packaging Engineering, 2014.

[2] Peng H, Zhu-Li L I, Department C, et al. On illustrator in Advertising Design and Development Trend of the Manifestation[J]. Journal of Guangdong Aib Polytechnic College, 2014.

[3] Ouyang C Y, Li L, Xiong Y J, et al. The Application of Green Materials in Product Packaging Design[J]. Advanced Materials Research, 2014, 